\title{
As Salvaguardas do Estado no Brasil
}

\author{
Enrique Ricardo Lewandowski \\ Professor Assistente Doutor da Faculdade de \\ Direito da Universidade de São Paulo
}

\section{INTRODUÇÃO}

A revogação dos atos institucionais e complementares pela Emenda Constitucional $\mathrm{n}^{\circ} 11 / 78$ consistiu, como se sabe, no primeiro passo em direção à volta do Estado de Direito no Brasil. Esse passo, recorda-se, somente foi possível na medida em que os promotores da abertura política ofereceram às Forças Armadas plenas garantias de que a Segurança Nacional, tal como concebida pela Escola Superior de Guerra - ESG, não seria colocada em risco por falta de instrumentos legais adequados à sua proteção, ou seja, em outros termos, na medida em que ficou assegurado aos militares e grupos a eles ligados o domínio da situação política na difícil fase de transição do arbitrio para a legalidade.

Como penhor de uma abertura controlada, o Presidente Geisel deixou incorporadas à Constituição as chamadas salvaguardas do Estado, integradas pelo Estado de Emergência e pelas Medidas de Emergência ${ }^{(1)}$.

As salvaguardas, apesar de haverem sido repudiadas por alguns, que as consideraram uma mera institucionalização dos atos de exceção, foram recebidas com aplauso por inúmeros juristas e políticos, que entenderam que a simples fixação de regras definidas, embora elásticas, relativas à defesa do Estado, representaram um importante avanço no sentido da volta à plenitude democrática.

(1) Observa-se que Afonso Arinos de Melo Franco, o Som de outro Sino: Breviário de um Liberal. Rio de Janeiro, Civilizacão Brasileira - UNZ, 1978, pág. 314, repudia a expressão salvaguardas que não considera apropriada para designar a segurança juridica do Estado. Assinala que a maioria dos dicionários não the atribui qualquer significado juridico e os que o fazem emprestam-lhe o sentido de salvo-conduto, de cautela individual contra crimes e ameaças ou de instrumentos de proteção no campo nuclear. Porém, em que pese a opinião do jurisconsulto, vale a pena manter essa designação, posto que ela já se tornou comum, não só nos meios políticos e jornalísticos, como também nos meios jurídicos e acadêmicos. 


\section{ASPECTOS TEÓRICOS}

Os povos ao longo da História constataram, muitas vezes a duras penas, que não pode haver segurança para os indivíduos sem que exista uma autoridade que a garanta. Essa noção, embora apreendida de modo intuitivo pelos homens desde tempos imemoriais, foi desenvolvida teoricamente, pela primeira vez, por Thomas Hobbes, no século XVII. Há mais de trezentos anos esse pensador explicava, em sua famosa obra o Leviatã, que «durante o tempo em que os homens vivem sem um poder comum capaz de os manter a todos em respeito, eles se encontram naquela condição que é chamada de guerra; e é uma guerra de todos os homens contra os homens (...). Numa tal situação não há lugar para a indústria, pois seu fruto é incerto; conseqüentemente não há cultivo da terra, nem navegação, nem uso das mercadorias que podem ser importadas pelo mar; não há construções confortáveis, nem instrumentos para mover e remover as coisas que precisam de muita força; não há conhecimento da face da terra, nem contagem do tempo, nem artes, nem letras; não há sociedade; e o que é pior de tudo, um constante temor e perigo de morte violenta; e a vida do homem é solitária, pobre, sórdida, embrutecida e curta»(2).

O poder a que se refere Hobbes é precisamente o Estado (Commonwealth, em inglês, Civitas, em latim), encarnado num soberano ou numa assembléia, ao qual os homens, através de um pacto coletivo, transferem seus direitos de autogoverno, para que este, em troca, lhes proporcione a segurança necessária ao pleno desenvolvimento de suas potencialidades.

Hobbes entendia que o Estado, no cumprimento dessa transcedental tarefa, goza da mais ampla autonomia e independência, pois, «na medida em que o fim dessa instituição é a paz e a defesa de todos, e visto que quem tem direito a um fim tem direito aos meios, constitui direito de qualquer homem ou assembléia o de ser juiz tanto dos meios para a paz e a defesa de tudo quanto possa perturbar ou dificultar estas últimas; e fazer tudo o que considere necessário ser feito, tanto antecipadamente, para a preservação da paz e da segurança, mediante a preservação da discórdia interior e da hostilidade vinda do exterior, como também depois de perdidas a paz e a segurança, para a recuperação de ambas» (3).

Essa concepção hobesiana do Estado, em que pesem mais de três séculos de pensamento liberal, continua até hoje a servir de fundamento à ação governamental, especialmente no que concerne à manutenção da segurança - amplamente compreendida - dos cidadãos. O único, embora importantíssimo, acréscimo sofrido por tal concepção,

(2) Cf. Thomas Hobbes, Leviathan, or Matter, Form, and Power of a Commonwealth Ecclesiastical and Civil, Great Books of the Western World, Enciclopaedia Britannica, (1952), pág. 85 .

(3) Ibidem, pág. 102. 
ao longo das lutas contra o absolutismo, foi o entendimento de que o valor liberdade encontra-se colocado no mesmo plano que o valor segurança. Isso significa que o Estado, em sua tarefa de assegurar a proteção aos indivíduos e às suas atividades, não pode ultrapassar aos indivíduos e às suas atividades, não pode ultrapassar determinados limites, isto é, não pode vulnerar a liberdade dos cidadãos, salvo se o fizer em defesa desse valor e mesmo assim dentro de parâmetros legais prévia e estreitamente definidos.

$O$ encontro do equilíbrio entre a manutenção da segurança, ou seja, da ordem social, e a preservação da liberdade constitui, na atribulada fase por que passa o mundo atualmente, um dos mais complexos problemas do Direito e da Política. Dalmo Dallari, inventariando as dificuldades abrigadas nessa questão, observa o seguinte: «Mantendo-se a liberdade ilimitada, como valor supremo que não pode ser restringido por qualquer outro, uma vez que nenhum lhe é superior, será bem difícil a preservação da ordem e, consequientemente, da coordenação em função de fins. Entretanto, se essa consideração levar ao excesso de restrições à liberdade, para que seja assegurada com máxima eficácia a preservação da ordem, esta acaba perdendo o caráter de meio para se converter em fim» ${ }^{(4)}$.

Essa questão, embora complexa, presume-se, atualmente, em encontrar, conforme assinala Ferreira Filho, «a justa medida que não retire do Estado as condições de eficiência do seu poder coercitivo nem sacrifique desnecessariamente a amplitude da liberdade individual» (5) Hoje não se cogita mais, pelo menos em termos de um posicionamento pragmático em face da realidade, na neutralização do Estado, como querem os ultralaterais, ou na sua extinção, como querem os marxistas ortodoxos, confiando a ordem social a processos auto-reguladores ou à disciplina espontânea e consciente dos indivíduos. Modernamente, aliás, liberais e marxistas, no plano da atividade política concreta, caminham na direção de um constante e acelerado fortalecimento do Estado. Nesse sentido, repara Dalmo Dallari que «pode-se afirmar que não há, presentemente, elementos concretos que permitam afirmar-se que o mundo está caminhando para a extinção do Estado», concluindo que, «o mundo sem Estados não tem as características de um futurivel, podendo ser aceito apenas como ideal utópico, sem apoio na realidade presente» ${ }^{(6)}$.

Nesse contexto vem à baila a problemática da defesa do próprio Estado, enquanto fiador da segurança dos indivíduos. Este, segundo nota Ferreira Filho, «não poderá cumprir sua missão, não logrará garantir a segurança individual se não puder resistir à agressão», ou

(4) Dalmo Dallari, Elementos de Teoria Geral do Estado, 5\% ed., São Paulo, 1979, pág. 113.

(5) Ferreira Filho, A Reconstruç̃o da Democracia: Ensaio sobre a institucionalização da Democracia no mundo Contemporâneo e em especial no Brasil, São Paulo, Saraiva, 1979, pág. 214.

(6) Dalmo Dallari, o Futuro do Estado, São Paulo, Saraiva, 1972, pág. 151. 
então, «se não contar com meios adequados para enfrentar as difi. culdades emergentes de graves perturbaçōes da ordem» (7).

Ocorre, porém, que a experiência dos países regidos por constituições democráticas tem demonstrado que os instrumentos normalmente postos à disposição do Poder Público são insuficientes para enfrentar situaçōes de gravidade excepcional que colocam em risco a sobrevivência do próprio Estado. Em razão disso, a técnica constitucional desenvolveu certos meios de defesa do Estado que podem ser empregados pelas autoridades em momentos de anormalidade, ampliando as restrições ordinariamente impostos à liberdade dos indivíduos, sem, no entanto, sair dos marcos que delimitam a ordem jurídica. A essas medidas de emergência os juristas chamam de direito de crise $^{(8)}$.

E interessante lembrar que os tratadistas fazem uma distinção entre as situações de crise que põem em perigo a sobrevivência do Estado e aquelas que colocam em risco a manutenção de determinado regime político. Paul Leroy, estudioso do assunto, observa que, no primeiro caso, as ameaças dirigem-se contra a integridade territorial ou a independência do Estado, podendo estas ter origem interna ou externa; no segundo caso, as ameaças voltam-se contra a ordem social e política vigente, dando ensejo à instauração de um «sistema institucional inspirado em outros princípios», o que reflete, em última análise, uma crise de legitimidade ${ }^{(9)}$.

Alguns autores, como Barthélemy y Duez, não aceitam a utilização do direito de crise para a defesa do regime político, mas apenas para a proteção do Estado (19). Outros, como Geneviève, alertam contra o perigo do emprego dos instrumentos de emergência quando o regime político não for democrático ${ }^{(11)}$.

Deve-se observar, no entanto, que é extremamente difícil estabelecer de antemão quais as situaçôes de crise que ameaçam a manutenção de certo regime político deixando incólume o Estado. Na verdade, se o Estado consiste, como quer Dalmo Dallari, na «ordem jurídica soberana que tem por fim o bem comum de um povo situado em determinado território», e se o regime político, na definição de Xifra Heras, constitui o «conjunto de forças políticas e de fins que realizam e inspiram o complexo normativo do Estado», segue-se que todo ata-

(7) Cf. Ferreira Filho, A Reconstrução..., cit., pág. 215.

(8) Para uma análise do direito de crise consulte-se: Ferreira Filho, o Estado de Sítio, São Paulo, (Revista dos Tribunais), 1964; Geneviève Camus, L'Etat de Necessité en Democxatie, Paris, Librairie Générale de Droit et de Jurisprudence, 1965, Paul Leroy, L'Organisation Constitutionelle et les Crises, Paris, Librairie Générale de Droit et Jurisprudence, 1966, Gerardo Morelli La Sospensione dei Diritto Fondamentali nello Stato Moderno, Milano, Giuffrè, 1966; e Giuseppe de Vergottini, Indirizzo Politico della Difesa e Sistema Constituzionale, Milano, Giuffrè, 1971.

(9) Cf. Paul Leroy, op. ẹit., págs. 13 e 14.

(10) Cf. Francisco Fernández Segado, El Estado de Excepción en el Derecho Constitucional Español. Madrid, EdERSA, 1977, pág. 162.

(11) Cf. Geneviève Camus, op. cit., págs. 64 a 78. 
que ao regime, ou seja, às forças e aos fins que servem de substrato à ordem jurídica estatal, dificilmente vai deixar de atingir também o próprio Estado e ameaçar a sua existência (12).

$E$ importante assinalar que essas questões afloram na medida em que a maioria dos sistemas de emergência não definem com precisão as situações em que as autoridades podem legitimamente lançar mão das medidas extraordinárias para debelar uma crise. Paul Leroy recorda que os regimes autoritários, via de regra, evitam definir com rigor as circunstâncias em que é lícito aos governantes empalmar poderes excepcionais, explicando que «o Executivo desejoso de os utilizar, mesmo em período praticamente normal, poderá fazê-lo sem violar os textos» ${ }^{(13)}$.

Esse problema sempre suscitou - e suscita até hoje - controvérsias entre os tratadistas. Alguns mostram-se favoráveis à enumeração taxativa das causas que podem determinar a decretação do estado de exceção, sendo esse o parecer de Leon Duguit, para quem as únicas hipóteses em que isso deveria ocorrer são as seguintes: guerra externa, insurreição armada ou greve geral. Outros entendem que basta apenas inscrever na Constituição, de modo genérico, os traços caracterizadores das situações de crise. Dentre os teóricos que assumem esta posição encontra-se Camus, que acredita que a gravidade e proximidade de uma ameaça contra o Estado são condições que por si só justificam o emprego de poderes extraordinários. Além dessas posições, existe ainda uma tese intermediária, que é a de Fernández Segado e de outros, segundo a qual a limitada abrangência de um arrolamento taxativo e a excessiva imprecisão de uma caracterização genérica podem ser obviadas pela enumeração exemplificativa das circunstâncias excepcionais «desde que estabeleçam com clareza as características que deverão possuir as restantes não mencionadas» (14).

Fernández Segado nota que com a enumeração das situações de crise, ainda que somente exemplificativa, fica afastada qualquer apreciação valorativa na decretação do estado de exceção, não importando considerar se uma determinada ameaça dirige-se contra o Estado ou apenas contra o regime, ou ainda se este é ou não democrático. Para o professor madrilenho, desde que ocorram na realidade fática os pressupostos fixados nas normas constitucionais (ou legais), a aplicação de medidas extraordinárias para neutralizar a situação de crise adquire plena legitimidade ${ }^{(15)}$.

Examinada a problemática da caracterização das situações de crise, faz-se necessário analisar a classificação dos vários sistemas de

(12) Cf. Dalmo Dallari, Elementos..., cit., pág. 104, e cf. Xifra Heras, Formas y Fuerzas Politicas, Barcelona, Bosch, (1958), pág. 162.

(13) Cr. Paul Leroy, op. cit.. pág. 68.

(14) Cf. Fernández Segado, op. cit., págs. 61 e 62.

(15) Ibidem, pág. 62. 
emergência, em função dos poderes concedidos às autoridades em circunstâncias excepcionais.

Esse assunto foi estudado pelo professor Ferreira Filho em diferentes obras. Num primeiro trabalho, o mestre da Universidade de São Paulo examina os grandes sistemas de defesa da Constituição, concluindo que estes podem ser distribuídos segundo três grupos. O primeiro corresponde aos sistemas que, em face de situações de anormalidade, suspendem no todo ou em parte a ordem constitucional, para concentrar nas mãos de um só indivíduo todo o poder, habilitando-o a solucionar os problemas emergentes de acordo com o seu exclusivo entendimento, irresponsabilizando-o por seus atos. Esses sistemas estabelecem ditaduras, cujo exemplo clássico constitui a magistratura romana extraordinária para a salvação da república. $O$ segundo grupo caracteriza-se por não alterar a ordem constitucional e nem tampouco a ordem legal, admitindo, todavia, a prática de qualquer ato necessário à superação da crise, sujeito, porém, a contraste judicial. Tal sistema, informa o autor, é o da lei marcial britânica e norte-americana. Finalmente, o último grupo distingue-se pela substituição da legalidade ordinária, própria para as situações de normalidade, por uma legalidade especial, transitória, para enfrentar a crise, dentro dos parâmetros constitucionais. Dentre esses sistemas inclui-se o estado de sítio ${ }^{(16)}$.

Em outra obra, Ferreira Filho adota a expressão sistemas de emergência, dividindo-os tout court, em sistemas rígidos e sistemas flexíveis. Dentre os primeiros alinha aqueles nos quais as medidas de exceção que podem ser adotadas numa situação de emergência são taxativamente enumeradas na norma legal. Esses sistemas, observa o constitucionalista da USP, são os preferidos na perspectiva liberal, porquanto estão mais próximos do ideal do Estado de Direito. Após a declaração de crise ocorre, simplesmente, uma substituição da legalidade ordinária por uma legalidade extraordinária. «Neste caso, como naquele - lembra Ferreira Filho -, a ação do Estado deve ajustar-se rigorosamente à legalidade, sob pena de invalidade do ato e responsabilidade criminal da autoridade». Além do tradicional estado de sítio, constitui exemplo de sistema rígido a suspensão do habeas corpus previsto na Constituição Americana (art. 1ㅜ, seção IX) ${ }^{(17)}$.

Os sistemas flexíveis são aqueles nos quais a lei não determina antecipadamente as medidas facultadas às autoridades para enfrentar uma grave crise. Nesse sistema pode-se empreender tudo o que for necessário - porém só o que for necessário, nota Ferreira Filho para restaurar a ordem abalada. A lei marcial é um instrumento típico dos sistemas flexíveis, na medida em que representa a oposição violenta do Poder Público contra invasões, insurreições, tumultos ou

(16) Cf. Ferreira Filho, o Estado..., cit., págs. 27 e 28.

(17) Cf. Ferreira Filho, A Reconstrucão.... cit., 215 e 216. 
resistências à lei. Consiste «na legítima defesa da ordem pública com o emprego da força armada pela autoridade responsável por essa ordem pública». Outro exemplo é o famoso art. 16 da Constituição francesa de 1958, que autoriza o Presidente da República a tomar as medidas exigidas pelas circunstâncias «quando as instituições da República, a independência do país, a integridade do seu território ou o cumprimento de seus compromissos internacionais estiverem ameaçados de maneira grave e imediata» (18).

Fazendo um balanço entre os sistemas rígidos e flexíveis Ferreira Filho conclui que, embora os primeiros excluam o arbitrio e sejam «mais favoráveis à segurança individual e menos arriscados para a democracia», deve-se notar que eles se revelaram inadequados para enfrentar a guerra contemporânea. Recorda que, «de há muito, os Estados que os adotaram já se viram obrigados a socorrê-los com outros instrumentos». Nesse sentido, lembra que, desde a $1^{\text {a }}$ Grande Guerra países como a França, a Grã-Bretanha, os Estados Unidos e até mesmo a Suiça, entre outros, tiveram de lançar mão de poderes extraordinários para enfrentar o conflito que exigia a total mobilização da economia e da sociedade. Modernamente, com o advento das armas nucleares e da guerra revolucionária, mais do que nunca, faz-se necessário dotar o Estado de uma certa flexibilidade nas respostas a esses desafios, flexibilidade essa inexistente nos sistemas rígidos, especialmente no estado de sítio, instrumento desenvolvido em outra época, em função de outras circunstâncias ${ }^{(19)}$.

\section{SALVAGUARDAS NO DIREITO COMPARADO}

O estado de sítio é um dos sistemas de emergência que maior acolhida encontrou entre os países que adotam o direito escrito. Tem origem no direito francês que, em 1791, pouco depois da promulgação da histórica Declaração dos Direitos do Homem e do Cidadão em 1789, instituiu o chamado état de siège, que autorizava a suspensão de determinadas garantias individuais durante o cerco de uma praça por forças inimigas. Esse instituto, depois de várias reformulações, adquiriu feição definitiva com a lei de 9 de agosto de 1849 - elaborada com fundamento no art. 106 da Constituição de 1848 - posteriormente modificada pela lei de 3 de abril de $1878^{(20)}$.

Esses diplomas, conforme ensina Ferreira Filho, distinguem dois tipos de estado de sítio: um real ou efetivo e outro político ou fictício. O primeiro diz respeito a um verdadeiro cerco de tropas hostis, cabendo, nesse caso, a declaração do estado de sítio ao comandante militar, ad referendum do Presidente da República, dependendo a sua

(18) Ibidem, págs. 216 a 220.

(19) Cf. Ferreira Filho, A Reconstrução..., cit., págs. 220 a 227.

(20) Cf. Ferreira Filho, O Estado... cit., págs. 74 a 76. V. também o verbete état do siège no Dictionnaire de la Constituition, $2^{\text {a }}$ ed. Paris, Cujas, 1978, org. por Raymond Barrillon et alif. 
prorrogação de autorização parlamentar. A segunda espécie de estado de sítio é decretado por lei, na hipótese de perigo eminente de guerra ou insurreição armada. Caso a Assembléia Nacional esteja em recesso, compete ao Presidente decretá-lo, sob condição de posterior ratificação pelo Legislativo, automaticamente convocado. Nos dois tipos de estado de sítio, os efeitos quanto às restrições de direitos dos cidadãos são iguais ${ }^{(21)}$.

A lei de 1849, modificada pela lei de 1878, outorgou às autoridades militares um poder de polícia ampliado, conferindo-lhes as seguintes prerrogativas: (1) o direito de perquisição, tanto à noite quanto de dia, nos domicílios dos cidadãos; (2) o direito de afastar da zona sujeita ao sítio os ex-condenados e os que lá não estejam domiciliados; (3) o direito de exigir a entrega de armas e de munições, bem como o de buscá-las e de apreendê-las; (4) o direito de proibir publicações e reuniões que possam provocar ou alimentar desordens. A justiça castrense passa a ser competente para o julgamento de civis. Mais tarde, as leis de 27 de abril de 1916 e de 23 de dezembro de 1952 alargaram a competência dos tribunais militares ${ }^{(22)}$.

Presentemente, as disposições legais que disciplinam o estado de sítio encontram-se amparadas pelo art. 36 da Constituição francesa de 1958. Esse dispositivo atribui a sua declaração ao Executivo (Conselho de Ministros), não podendo este fazê-lo por prazo superior a doze dias sem anuência do Parlamento.

O direito francês criou também o estado de urgência (ètat d'urgence) para os casos em que, embora não esteja configurado um conflito armado interno ou externo, a ordem pública se encontre ameaçada. Tal instituto, criado por uma lei de 3 de abril de 1955, alterada em 15 de abril de 1960, consiste num regime especial de restrição de liberdades, inspirado no estado de sítio, dele se diferenciando por seu caráter mais rigoroso e pelo fato de que a ampliação do poder de polícia beneficia as autoridades civis e não as militares. O estado de urgência originou-se da necessidade de controlar as agitaçôes que precederam a independência da Argélia, que, na época, como se sabe, era uma colônia da França. A decretação do estado de urgência, circunscrito territorialmente e limitado a um prazo não superior a doze dias, cabe ao Conselho de Ministros, dependendo sua prorrogação de autorização legislativa. Sua vigência confere às autoridades civis o poder de interferir no direito de ir e vir dos cidadãos, bem como o poder de controlar locais abertos ao público, impedindo sua utilização ou determinando seu fechamento. A lei que prorroga a sua duração pode ampliar o poder de polícia das autoridades, particularmente no que concerne à faculdade de perquisição de suspeitos e ao controle dos meios de comunicação. Esse instrumento foi posto em prática em três ocasiões: em 1955 e em 1960 sobre os départements do Norte da África; em 1961 sobre todo o território metropolitano,

(21) Cf. Ferreira Filho, o Estado..., cit., págs, 76 e 77.

(22) Cf. Ferreira Filho, o Estado.., cit., pág. 77, e cf. verbete état de sièg., cit. 
para dominar uma tentativa de golpe intentada pela Organisation de l'Armèe Secrète (OAS), contrária à emancipação da Argélia (23).

Paralelamente ao estado de sítio e ao estado de urgência, a Constituição francesa, em seu art. 16, concede plenos poderes ao Presidente da República em circunstâncias excepcionais. Esse instituto, criado sob a égide do General de Gaulle, Presidente do Conselho de Ministros à época da elaboração dessa Constituição, inspirou-se nas dificuldades enfrentadas pelo governo francês por ocasião da $2^{\text {a }}$ Guerra Mundial, quando o estado de sítio mostrou-se totalmente inadequado para enfrentar a situação ${ }^{(24)}$.

O citado dispositivo constitucional alarga os poderes presidenciais nos seguintes termos: "Quando as instituições da República, a independência do país, a integridade do seu território ou o cumprimento de seus compromissos internacionais estiverem ameaçados de maneira grave e imediata, e o funcionamento regular dos poderes públicos constitucionais estiver interrompido, o Presidente tomará as medidas exigidas por essas circunstâncias, após consultar oficialmente o Primeiro Ministro, os presidentes das assembléias, bem como o Conselho Constitucional.

«Ele (o Presidente) informará a Nação através de uma mensagem.

«Essas medidas deverão estar inspiradas por uma vontade de assegurar aos poderes públicos constitucionais, com a mínima demora, os meios de cumprir a sua missão. O Conselho Constitucional será consultado.

«O Parlamento se reunirá de pleno direito.»

«A Assembléia Nacional não poderá ser dissolvida durante 0 exercício dos poderes excepcionais».

E interessante observar que o art. 16 da Constituição francesa confere ao Presidente, conforme assinalam seus críticos, poderes verdadeiramente ditatoriais, posto que não há predeterminação de espécie alguma quanto às medidas que poderão ser empreendidas. Além disso, observam que as situações em que esse dispositivo pode ser posto em prática também não são definidas com clareza, permitindo uma interpretação eminentemente subjetiva.

Para Maurice Duverger, por exemplo, «o art. 16 faz o regime correr um perigo mortal. Permite, com efeito, que um Presidente, sem escrúpulos derrube a República, sem a sombra de uma dificuldade, revestido um golpe de Estado de uma aparência de legalida-

(23) Cf. verbete état d'urgence in Dictionaire, cit.

(24) Cf. Ferreira Filho, A Reconstrucão.... cit., pág. 218. Consulte-se ainda o verbete article 16 do Dictionnaire..., cit., e Jean Louis Debré, La Constituition de la Ve. Republique, Paris, Presses Universitaires de France, 1975, especialmente o capitulo «Les étapes de la redaction de l'article $16 \%$. 
de, suprimindo todos os obstáculos jurídicos que lhe impediriam o êxito» (25).

Georges Burdeau, no entanto, entende que o texto do art. 16 não dá margem a qualquer ambigüidade. Segundo o professor francês, para que o Presidente possa lançar mão dos poderes extraordinários nele previstos é imprescindível que duas variáveis estejam conjugadas: de um lado, a ocorrência de circunstâncias de «particular gravidade»; de outro, a comprovação da «incapacidade material dos poderes públicos». Assim, poìs, sublinha que não basta a superveniência de uma grave crise simplesmente, mas é necessário que os órgãos do Estado se encontrem impedidos de desempenhar suas funçōes. Afora isso, observa Burdeau que, embora a decisão de colocar em vigor o art. 16 escape a qualquer controle, quer político, quer judicial, os atos presidenciais decorrentes dos poderes de emergência podem ser submetidos aos tribunais competentes ${ }^{(26)}$.

É interessante reparar que Cretella Junior, estudando o problema da responsabilidade do Estado por atos empreendidos em circunstâncias excepcionais, explica que estes tem por base o estado de necessidade. "O status necessitatis - ensina o mestre - ocorre em momentos de graves perturbações ou comoções sociais, quer por fatos exteriores, ou de guerra, quer fatos internos, ou de revolução, calamidade pública», sendo, assim, "exclusivo da obrigação de indenizar e, portanto da responsabilidade, afigurando-se como situação em que predomina o interesse geral sobre o interesse pessoal, conveniência e mesmo direitos individuais»(27). Esse ensinamento demonstra que, apesar de facultado o recurso aos tribunais nas situações de emergência, a expectativa de êxito na responsabilização do Estado por algum excesso é bastante limitada.

As faculdades do art. 16 somente foram utilizadas uma única vez desde que foram inscritos na Constituição da V República. De Gaulle empregou tais poderes de 23 de abril a 29 de setembro de 1961, para enfrentar a tentativa de golpe de estado levada a cabo pelos Generais Challe, Jouhaud, Salan e Zeller, da OAS, em plena crise da Argélia. Para superar a situação o Presidente adotou, dentre outras, as seguintes medidas: (1) declaração e prorrogação do estado de urgência até 15 de julho de 1962 ; (2) estabelecimento de providências especiais para neutralizar as pessoas perigosas à ordem pública: desterro, residência obrigatória e internamento administrativo; (3) demissão e reforma de funcionários civis e militares, sem aposentadorias ou vantagens; (4) modificação da lei orgânica da magistratura;

(25) Apud Ferreira Filho, A Reconstrucãa..., cit., pág. 221.

(26) Georges Burdeau Les Libertés Publiques, Paris, Librairie General Droit et de Jurisprudence, 1976, págs. 54 e 55. V. também do mesmo autor, Droit Constitutionnel et Instituitions Politiqnes, 17* ed., Paris, Librairie General de Droit et de Jurisprudence, 1976, pags. 638 a 641 .

(27) Cretella Júnior, Tratado do Direito Administrativo, vol. VIII, Rio de Janeiro São Paulo, Forense, 1970, pág. 103 
(5) criação de um Alto Tribunal Militar (Haute Tribunal Militaire) e nomeação de seus membros, para julgamento de crimes praticados contra a segurança; (6) instituição de outro tribunal militar e nomeação de seus membros, para apreciação de causas de menor importância; (7) determinação de regras excepcionais de processo penal; (8) proibição de determinadas publicações periódicas ${ }^{(28)}$.

Avaliando o resultado da aplicação dessas medidas, Ferreira Filho observa que o saldo foi positivo: «Fato é que elas foram eficazes e contribuíram decisivamente para que se sufocasse a rebelião militar eclodida na Argélia. E, seja pela virtude de seu aplicador, o General De Gaulle, ou não, de modo algum levaram à destruição a democracia francesa» (29).

Nos países anglo-saxônicos as crises são enfrentadas mediante o recurso à lei marcial (martial law) britânico. Trata-se como já foi visto de uma espécie de legítima defesa do Estado. Para H. S. Bhatia a lei marcial «é tão necessária à soberania de um Estado como o poder de declarar e fazer a guerra» (30). Albert Dicey define-a como «o direito que, na common law, possuem a Coroa e seus agentes de repelir a força pela força, em caso de invasão, insurreição, tumulto ou, de modo geral, de resistência violenta à lei» ${ }^{(31)}$.

Nos Estados Unidos a lei marcial encontra fundamento - embora nâo seja diretamente mencionada - no art. 1․, seção IX, inciso 2 , da Constituição que autoriza a suspensão do habeas corpus «em caso de rebelião ou invasão, quando tal for exigido pela salvação pública». Apesar de alguns autores arrolarem a suspensão do habeas corpus entre os sistemas rígidos, a verdade é que ela tem ensejado a aplicação de medidas mais amplas. Lincoln, por exemplo, exorbitou de seus poderes constitucionais, em 1863, em plena Guerra Civil, ao ordenar o julgamento de civis por tribunais militares nos territórios conflagrados e ao determinar a intervenção nos Estados rebeldes, com base no referido dispositivo. Atualmente, a doutrina e a jurisprudência têm aceito pacificamente a decretação da lei marcial, sendo que entre os norte-americanos o Presidente ou o Governador de Estado é competente para fazê-lo. É interessante notar, todavia, que os tribunais podem entrar no mérito dessa proclamação; em 1931, no Texas, o Governador declarou a lei marcial no território do Estado, porém, esse ato foi invalidado pela Suprema Corte ${ }^{(32)}$.

É importante ressaltar que, embora seja facultado às autoridades, durante a lei marcial, a adoção de quaisquer meios que considerem adequados para a superação das ameaças à ordem e à segurança, «ela não exclui - conforme ensina Ferreira Filho - a responsabilidade

(28) Cf. Ferreira Filho, A Reconstruçã..., cit., págs. 219 e 220, e cf. também o verbete article 16 in Dicionnaire..., cit.

(29) Cf. Ferreira Filho, A Reconstrucão..., cit., pág. 220.

(30) H. S. Bhatia, Martial Law, New Delhi, Deep \& Deep, 1979, pág. 24.

(31) Apud Ferreira Filho, op. cit.. pág. 312, e H. S. Bhatia, op. cit., pág. 29.

(32) V. Afonso Arinos, op. cit., pág. 312, e H. S. Bhatia, op. cit., pág. 29. 
por todos os atos que, sendo abusivos ou excessivos, não eram necessários em face das circunstâncias». A apreciação da adequação entre as medidas utilizadas e a necessidade determinada pela situação enfrentada compete aos tribunais convocados para apreciar os atos das autoridades durante a emergência ${ }^{(33)}$.

Além disso, deve-se notar que a lei marcial, apesar de enquadrada entre os sistemas flexíveis, por não predeterminar as respostas às situações de emergência, possui uma abrangência relativamente limitada. Com efeito, esse instrumento só pode ser empregado legitimamente quando em presença de uma perturbação da ordem que se exteriorize por alguma manifestação violenta. $\bar{E}$, pois, o meio ideal para debelar invasões, insurreições, tumultos, desordens, etc. Não se presta, porém, para enfrentar ameaças cuja violência esteja ainda em gestação ou crises que exijam uma pronta atuação dos poderes públicos, sem no entanto configurarem uma situação de efetivo conflito.

É por isso que Karl Loewenstein conclui que as constituições dos países anglo-saxônicos não prescreverem qualquer disposição para as situações de crise. Observa que em momentos de emergência ocorre uma delegação de poderes do parlamento ao governo, «quer através de uma lei relacionada com a situação de crise futura, ou ad hoc quando a situação de crise já se tenha produzido de fato». Lembra o Fimergency Powers Act inglês, de 1920, que concede poderes especiais ao governo em circunstâncias excepcionais internas. Essa lei foi aplicada apenas uma vez, em 1926, durante uma greve geral. As outras transferências de poderes somente são realizadas na eminência de crises. Isso aconteceu na $1^{\text {a }}$ Guerra Mundial, com o Defense of the Realm Act de 1914, e na $2^{\text {a }}$ Guerra Mundial, com os Emergency Powers Acts de 1930 e de 1940. Essa técnica de delegação de poderes desenvolvida nas épocas de guerra passou a ser utilizada também em tempos de paz. Primeiramente, pelos conservadores, para debelar a crise econômica de 1931, e, mais tarde, pelos trabalhistas, em 1945, para empreender um programa de reformas sociais e econômicas ${ }^{(34)}$.

Nos Estados Unidos, informa Loewenstein, ocorre algo análogo. Nas duas guerras mundiais o Congresso concedeu ao Presilente, na qualidade de chefe supremo das Forças Armadas, plenos poderes para dirigir a defesa nacional e conduzir a guerra. Tais poderes compreenderam o controle sobre as indústrias de guerra, os transportes, as comunicações, os preços, etc. Dois diplomas legais destacaram-se nessa fase, fortalecendo as atribuições de Roosevelt: o First War Powers Act, de 1941, e o Second War Powers Act, de 1942. Depois da Guerra, os poderes presidenciais extraordinários foram suspensos, para serem retomados mais tarde, parcialmente, durante a Guerra da Coréia, em $1950^{(35)}$.

(33) Cf. Ferreira Filho, A Reconstrucão..., cit., pág. 217.

(\$4) Ct. Karl Loewenstein, Teoria de la Constitucion, 2a ed. Barcelona, Ariel, 1976, pág. 290 .

(35) Ibidem, op. eit., pág. 291. 
Entre a experiência norte-americana e a inglesa registra-se uma importante diferença, segundo Loewenstein. Enquanto que na Inglaterra o Primeiro-Ministro e o Gabinete de Guerra exerceram uma verdadeira ditadura constitucional, nos Estados Unidos o Congresso jamais alienou totalmente o seu direito de participar na determinação das decisões políticas ${ }^{(36)}$.

Também a Suiça desenvolveu um sistema de delegação de poderes durante as duas grandes guerras. Nessas ocasiões o Legislativo (Assembléia Federal) outorgou ao Executivo (Conselho Federal) as mais amplas competências para enfrentar a situação de emergência nacional por que passava o país. Em 1914, o parlamento suíço baixou a seguinte resolução: «A Assembléia Federal concede poder ilimitado ao Conselho Federal para tomar todas as medidas necessárias a manter a segurança, a integridade e a neutralidade da Suíça e a defender o crédito e os interesses econômicos do País». Ao longo dos quatro anos de duração do conflito, o Executivo emitiu cerca de 1.440 leis (ordenações), contra apenas 220 originadas do Legislativo. Em 1939, no limiar da $2^{\text {a }}$ Guerra Mundial, nova resolução é aprovada, repetindo, praticamente, a primeira. «A Assembléia Federal concede ao Conselho Federal poder e mandato para tomar as medidas necessárias para manter a segurança, a independência e a neutralidade da Suíça, e para defender o crédito e os interesses econômicos do país». Durante os seus anos de guerra, o Conselho Federal decretou 1.850 ordenações, ao passo que a Assembléia Federal, no mesmo período, votou apenas 10. Algumas dessas leis restringiram direitús individuais, como a que instituiu o trabalho obrigatório ou a que estabeleceu a censura postal e telefônica. Com a restauração da paz, cessam os plenos poderes do Executivo ${ }^{(37)}$.

Finalizando, observa-se que os instrumentos de defesa analisados nesta seção constituem, por assim dizer, as matrizes a partir das quais foram desenvolvidos os demais sistemas vigentes nos vários países. Basicamente, a opção é feita por um dos dois modelos clássicos: ou o estado de sítio ou a lei marcial. O primeiro é o preferido pelos países que adotam o direito escrito, enquanto que o segundo é o mais aceito por aqueles regidos pelo direito consuetudinário. Em paralelo com esses dois sistemas, muitos países, em situação de crise de excepcional gravidade, utilizam a técnica da declaração de poderes, fórmula essa que provou dar bons resultados durante as duas últimas guerras mundiais. Além disso, modernamente, muitas nações, procurando aperfeiçoar os seus instrumentos de defesa para enfrentar com êxito as vicissitudes do mundo moderno, voltam os seus olhos

(36) Ibidem, loc. cit.

(37) Dados de Afonso Arinos, op. cit., pág. 322. Para uma análise mais aprofundada do tema consulte-se Münci Kapani, Les Pouvoirs Extraordinaires de L'Executif en Temps de Guerre et de Crise Nationale, Genève, 1949; Rudolf Zihlmann, Legitimitat und Legalitat des Notrechts, Bern, 1950; André Manuel, Les Pleins Poucoirs em Droit Public Federal Suisse, Lauranne, 1953, Werner Suter, Notrecht un Ausserorodentliche vollmachten im Schweizerischen Bundesstaatsrecht, Zürich, 1960. 
para o art. 16 da Constituição francesa, em busca de uma solução que apresente, simultaneamente, as características de segurança tanto do Estado quanto dos cidadãos — e flexibilidade.

\section{O ESTADO DE SíTIO}

O Brasil, antes mesmo da proclamação da República, adotou o état de siège francês. Com efeito, conquanto não mencionasse expressamente o estado de sítio, a Constituição do Império, de 1824, admitia em seu art. 179, XXXV, que, por ato especial do Poder Legislativo, fossem dispensadas «algumas das formalidades que garantem a liberdade individual», por tempo determinado, «nos casos de rebelião ou invasão de inimigos, pedindo a segurança do Estado».

A Constituição Republicana de 1891 incorporou ao seu texto a expressão estado de sítio tratando, porém, do assunto de forma muito vaga, fato esse que gerou inúmeros abusos. Durante a fase inicial da República, qualquer agitação social, ou mesmo qualquer oposição mais enérgica ao Governo, ensejava a suspensão das garantias constitucionais sob a justificativa de que a segurança da República assim o exigia ou de que se configurava a situação de commocão intestina, duas fórmulas que permitiam, segundo o art. 80, a decretação do estado de sítio. Deve-se notar, todavia, que essa atribuição competia ao Congresso Nacional, salvo nos momentos em que este estivesse em recesso, quando a competência passava a ser do Executivo.

A Constituição de 1934, procurando cercear os desmandos provocados pela ambigüidade do dispositivo constitucional anterior, passou a regular o estado de sítio com minúcias, em seu art. 175, cabendo ao Presidente da República, depois de autorizado pelo Legislativo, decretá-lo. O \& 15 do referido artigo previa uma forma qualificada de estado de sítio em caso de guerra, ao qual ficava equiparada, por força da Emenda Constitucional $\mathrm{n}^{\circ}$ 1, «a commoção intestina grave, com finalidades subversivas das instituições políticas e sociais». Essa extensão do conceito de guerra, provocado pelo temor da Intenton?. Comunista, facilitou, segundo Ferreira Filho, o golpe de 1937 (38).

A Carta de 1937, inspirada nas Constituições autoritárias da Polônia, Alemanha e Itália, entre outras, cria duas novas figuras - na verdade novas versões do estado de sítio - que podiam ser colocadas em prática pelo Presidente da República: a primeira, o estado de emergência, «em caso de ameaça externa ou na iminência de perturbações internas, ou existência de concerto, plano ou conspiração, tendente a perturbar a paz pública ou pôr em perigo a estrutura das instituições, a segurança do Estado ou dos cidadãos»; a segunda, o estado de guerra, quando «se torne necessário o emprego das forças armadas para a defesa do Estado». A própria Constitui-

(38) Cf. Ferreira Filho, Comentários à Constituiçío Brasileira, são Paulo, Saraiva, 1977, pág. 126. 
ção, de forma absolutamente inusitada, declarou instalado, em seu art. 186, o estado de emergência em todo o território nacional. Essa situação excepcional somente foi superada em 1945, pela Lei Constitucional $\mathrm{n}^{\circ} 16$.

A Constituição de 1946 retornou quase que integralmente à formulação feita em 1934, rejeitando, contudo, o adendo introduzido pela Emenda $n^{\circ}$ 1. Reafirma-se no texto constitucional a competência do Congresso para decretar o estado de sítio. O Presidente só podia fazê-lo nos momentos de recesso parlamentar.

E interessante notar que «de 1946 a 1961, da promulgação da Constituição à renúncia do Presidente Jânio Quadros - conforme lembra Ferreira Filho - , foi raro e breve o uso do estado de sítio. A crise da renúncia, porém, abriu a prática do estado de sítio de fato, ou seja, sem sua declaração expressa e legal. $\mathrm{Na}$ verdade, daí em diante, vários vezes as autoridades, sobretudo militares, tomaram medidas só cabíveis decretado o estado de sítio, sem que este o fosse, principalmente porque para a solução das crises se pretendia alterar a Constituição, o que era por esta proibido durante a suspensão das garantias constitucionais $(\ldots)$. Isso se tornou rotineiro após a Revolução de Março, apesar de os atos constitucionais revolucionários facilitarem sobremodo a instalação jurídica do estado de sítio» (39).

Deve-se sublinhar, porém, que as Constituições de 1967 e de 1969 não ousaram inovar em matéria de instrumentos de defesa do Estado. Mantiveram-se presas, em linhas gerais, ao texto de 1946 que, por sua vez, estava calcado no modelo de 1934. Tanto as hipóteses fundamentadoras do estado de sítio como as medidas autorizadas durante a sua vigência são bastante assemelhadas nesses diplomas. A única novidade digna de nota introduzida no instituto consistiu em retirar do Congresso a tradicional prerrogativa de decretar o sítio, transferindo-a para o Executivo. Essa providência, conforme se recorda, foi tomada inicialmente pelo Ato Institucional $n^{\circ}$ 1/64 e depois repetida pelo Ato $n^{\circ} 2 / 67$, para finalmente ser incorporada às Constituições revolucionárias.

A Constituição de 1969, até a promulgação da Emenda n $11 / 78$, facultava ao Presidente da República a decretação do estado de sítio nos casos de «grave perturbação da ordem ou ameaça de sua irrupção» ou ainda no caso de guerra, por um prazo de 180 dias, prorrogável se persistissem as razões que o determinaram (art. 155, I e II e art. 156) (40). Durante esse período o Governo ficava autorizado a empregar as seguintes medidas: (1) obrigação de residência em localidade determinada; (2) detenção em edifícios não destinados aos réus de crimes comuns; (3) busca e apreensão em domicílio;

(4)

(39) Cf. Ferreira Filho, Comentários..., cit., págs. 126 e 127.

(40) Ferreira Filho informa no Curso de Direito Constitucional, São Paulo, Saraiva, 1975, pág. 309, que a duração máxima do estado de sítio é de 360 días, não sendo lícita a prorrogaçāo, salvo em caso de guerra. 
suspensão da liberdade de reunião e de associação; (5) censura de correspondência, da imprensa, das telecomunicações e diversos públicas; e (6) uso ou ocupação temporária de bens das autarquias, empresas públicas, sociedade de economia mista ou concessionárias de serviço público, assim como a suspensão do exercício do cargo, função ou emprego nas mesmas entidades (art. 155, § 2, letra a a f).

Além dessas medidas, podia o Presidente, ouvido o Conselho de Segurança Nacional, em circunstâncias de excepcional gravidade, lancar mão de outras, desde que previamente estabelecidas (art. 155, $\S 3^{\text {^). }}$.

Observa-se, contudo, que a manutenção do estado de sítio dependia da anuência do Congresso, ao qual deveria ser enviado o decreto presidencial, para apreciação, dentro do prazo de cinco dias a contar de sua emissão, acompanhado da justificativa correspondente (art. 156, § 19). O não acolhimento da mensagem do Executivo suspendia automaticamente o sítio.

Essas características colocam o estado de sítio, tal como definido acima, na categoria dos instrumentos rígidos no que concerne à defesa da ordem pública, sendo, pois, de difícil aplicação. Primeiramente, deve-se observar que a ocorrência de «grave perturbação da ordem ou ameaça de sua irrupção» é fato raro e de complexa caracterização. Aliás, a exegese dessa expressão deve ser necessariamente parcimoniosa, porquanto, como já afirmava Rui Barbosa ao examinar o assunto, «nas constituições onde se autoriza essa interceptação da ordem constitucional, os requisitos postos ao exercício deste arbítrio hão de entender-se sob a interpretação mais limitativa. Pertencem à classe dos restringenda e não à dos amplianda» (41). Ademais, a enumeração das medidas de exceção não permite qualquer inovação no que respeita ao cerceamento das liberdades individuais. A faculdade que tem o Presidente de ampliar as restrições, estabelecidas no $\$ 3^{\circ}$ do art. 155, perde muito em flexibilidade na medida em que depende de oitiva do Conselho de Segurança Nacional e de previsão legal anterior.

Assim, pois, quando o Governo começou a receber pressões no sentido da revogação dos atos institucionais e complementares, verificou-se que, à luz dos conceitos de Segurança Nacional imperantes nos círculos castrenses e nos meios governamentais, era totalmente impossível a volta pura e simples ao sistema de emergência estabelecido na Constituição de 1969. Tratou-se, então, de criar novos instrumentos que, acoplados a um estado de sítio reformulado, assegurassem às autoridades revolucionárias a necessária flexibilidade para enfrentar com êxito as ameaças ao regime.

A Emenda Constitucional $n^{\circ} 11 / 78$, que representou o primeiro passo da abertura política promovida pelo Presidente Ernesto Geisel, superou o impasse, ao substituir os instrumentos de exceção revolucionários pelas chamadas salvaguardas do Estado. A reforma da Cons-

(41) Cf. Rui Barbosa, República: Teoria e Prática, Petrópolis, Vozes, 1978, pág. 290. 
tituição, recorda-se, ao revogar os atos institucionais e complementares promoveu, simultaneamente, a reestruturação parcial do estado de sítio, introduzindo, ao lado deste, no Capítulo V do Título II, o estado de emergência e as medidas de emergência.

$\mathrm{Na}$ verdade, o estado de sítio não sofreu nenhuma alteração substancial, continuando, portanto, a apresentar-se como um instrumento rígido. A flexibilidade na defesa das instituições, como se verá mais adiante, foi ensejada pelas novas salvaguardas. Graças a elas, repita-se, foi possivel ao General Geisel reunir o necessário consenso da base de sustentação militar do regime para a supressão dos atos revolucionários.

No que concerne ao estado de sítio, a Emenda Constitucional $n^{\circ}$ 11/78 introduziu, basicamente, duas alterações. Em primeiro lugar ampliou as hipóteses em que este pode ser cogitado. Tal ampliação deu-se pelo aumento do componente de subjetividade na apreciação das circunstâncias fundamentadoras do sítio. Este passa a ser admitido «no caso de guerra, ou a fim de preservar a integridade e a independência do país, o livre funcionamento dos poderes e de suas instituições, quando gravemente ameaçados ou atingidos por fatores de subversão. A segunda inovação consistiu no acréscimo, ao rol de medidas autorizadas durante a exceção, da possibilidade de «intervenção em entidades representativas de classe ou categorias profissionais». No mais, foram mantidas as disposições anteriores à reforma.

Essas duas novidades defluem diretamente da Doutrina de Segurança Nacional, desenvolvida pela ESG, refletindo sua preocupação com a guerra revolucionária comunista, especialmente com suas etapas iniciais. Com efeito, a alteração introduzida pela Emenda $n^{\circ}$ 11/78 amplia bastante a discricionariedade do Presidente da República na apreciação da conveniência da decretação do estado de sítio, ao admití-lo na simples ocorrência de «fatores de subversão». Essa expressão, nota-se logo, é extremamente vaga e ambígua, permitindo as mais variadas interpretações, como, aliás, foi feito num passado recente. Por outro lado, a inclusão da intervenção em sindicatos na enumeração das medidas possíveis durante o sítio torna factível o estrito controle do movimento trabalhista que é, segundo as teses da Segurança Nacional, a primeira vítima da subversão comunista.

É preciso observar, todavia, que essa relativa flexibilidade introduzida no instituto é anulada pela manutenção das demais disposições vigentes antes da reforma constitucional, principalmente as que se referem ao controle, a posteriori, do ato presidencial pelo Congresso (art. 156, $\S 4^{\circ}$ ) - que pode suspender a exceção - e as que tratam da limitação do prazo de duração do sítio, que continua sendo de 180 dias, prorrogável por igual período (art. 156, § $3^{\circ}$ ). Esses óbices são afastados pelas novas salvaguardas, como será visto mais adiante.

Finalmente, vale lembrar que, segundo preceitua o parágrafo único do art. 157, a inobservância de qualquer das prescrições, relati- 
vas ao estado de sítio, torna ilegal a coação e permite ao paciente recorrer aos tribunais, que continuam funcionando sem interrupção ao longo da situação excepcional.

\section{AS NOVAS SALVAGUARDAS}

A Emenda Constitucional $n^{0} 11 / 78$ criou, como se sabe, dois novos instrumentos de defesa do Estado que, embora derivados do antigo état de siège, incorporam em sua estrutura algumas das características dos sistemas de emergência flexíveis. Esses institutos, comparados com o estado de sítio, conferem, segundo alguns, poderes quase que ditatoriais ao Presidente da República. Na prática, dizem os críticos, introduziram na Constituição algumas das mais arbitrárias disposições do Ato Institucional $n^{0}$ 5/68, sem dúvida o mais rigoroso instrumento jurídico do período de exceção.

$O$ estado de emergência, que é um dos novos instrumentos introduzidos pela Emenda $n^{\circ} 11 / 78$ no texto da Carta de 1969, pode ser decretado pelo Presidente da República, depois de ouvido o Conselho Constitucional, quando forem exigidas «providências imediatas» em caso de guerra ou para "preservar a integridade e a independência do país», o livre funcionamento dos poderes e de suas instituições, quando gravemente ameaçados por fatores de subversão por fatores de subversão» (caput dos arts. 156 e 158) (42).

Essa fórmula, em si mesma considerada, em nada se distingue daquela que fundamenta o estado de sítio, exceto quanto à alegação de urgência, valendo, portanto, a argumentação acima expendida na qual se sublinhou a vagueza e a ambigüidade do conceito de «subversão», que pode variar enormemente em função das convicções políticas e ideológicas de seus aplicadores.

As medidas autorizadas durante o estado de emergência são iguais às admitidas no estado de sítio, consistindo, repita-se, nas seguintes: (1) obrigação de residência em localidade determinada; (2) busca e apreensão em domicílio; (4) suspensão de liberdade de reunião e de associação; (5) intervenção em entidades representativas de classes ou categorias profissionais; (7) censura de correspondência, da imprensa, das telecomunicações e diversões públicas; e (8) uso ou ocupação temporária de bens das autarquias, empresas públicas, sociedades de economia mista ou concessionárias de serviços públicos, bem como a suspensão do exercício de cargo ou emprego nas mesmas entidades (art. 156, $\S 2^{\circ}$ e art. 158, $\S 1^{\circ}$ ).

(42) O Conselho Constitucional inspirou-se no órgão do mesmo nome previsto nos arts. 56 a 63 da Constituição francesa, que se compõe de nove membros: três indicados pelo Presidente da República, três pelo Presidente da Assembléia e três pelo Presidente do Senado, cabendo a Presidência do Conselho a um dos membros indicados pelo Presidente da República. O colegiado criado pelo art. 159 da Emenda no 11/78 é presidido pelo Presidente da República, e dele participam, como membros natos, o Vice-Presidente da República, os Presidentes do Senado Federal e a Câmara dos Deputados, o Ministro da Justiça e um Ministro representante das Forças Armadas. 
Quanto à duração do estado de emergência, observa-se que ele somente pode ser decretado por dias, metade do prazo admitido para o estado de sítio, que é de 180 dias. Em ambos os casos permite-se uma prorrogação por igual periodo (art. $156, \S 3^{\circ}$ e art. 158, $\S 2^{\circ}$ ).

Assim, pois, é possível constatar, numa primeira análise, que o estado de sitio e o estado de emergência praticamente nenhuma diferença apresentam no que respeita aos fundamentos que os justificam, às medidas coercitivas autorizadas e ao prazo de duração. Entretanto, os dois institutos distinguem-se num ponto de fundamental importância, qual seja, o da intervenção do Congresso na validade do ato que suspende as garantias individuais. No estado de sítio, como foi visto, o Presidente é obrigado a remeter o decreto responsável por sua instauração ou prorrogação, acompanhado de justificativa, dentro de cinco dias a contar de sua emissão, ao Legislativo, que pode ou não referendá-lo. Caso os parlamentares o rejeitem, cessa de jure a exceção. $\mathrm{Na}$ hipótese de decretação ou de prorrogação do estado de emergência, a decisão presidencial é meramente comunicada ao Congresso, cinco dias depois de tomada pelo Chefe de Governo (art. 158, $\S 3^{\circ}$ ). O Legislativo, nesse caso, passa a ser um mero expectador da aplicação de um dos mais violentos remédios para preservação das instituições existentes em todo o ordenamento constitucional.

Como se verifica, o Presidente tem a mais ampla autonomia para decretar o estado de emergência, posto que não se encontra tolhido de qualquer modo pelos demais Poderes da República. Nem ao Congresso, nem ao Judiciário, é dado entrar no mérito do ato presidencial. Os tribunais podem, no máximo, examinar seus aspectos formais e os eventuais abusos praticados pelos executores da medida ${ }^{(43)}$. A consulta ao Conselho Constitucional é meramente formal, não possuindo caráter vinculante.

Esses fatos, somados à imprecisão da hipótese constitucional que o fundamenta, conferem ao estado de emergência uma enorme flexibilidade, tornando-o um instrumento apto a combater com êxito a «subversão», nos termos pretendidos pela Doutrina de Segurança Nacional, embora com evidente prejuízo para a garantia dos direitos fundamentais dos cidadãos.

Apesar da flexibilidade do estado de emergência, o seu desencadeamento é sempre problemático, pois implica a presunção de que o País e suas instituições estariam correndo grave risco. A admissão oficial desse fato, evidentemente, traz consigo inúmeras dificuldades não só internamente como também externamente. Para lembrar apenas algumas pode-se citar a perda de prestígio do Governo, o arrefecimento da economia e a inquietação da população, fatores esses que, muitas vezes, podem exacerbar a crise que se pretendia ver superada. Para obviar esses problemas foram introduzidas na Constituição, ao lado dos demais instrumentos de defesa do Estado, as medidas de 
emergência que podem intervir na realidade social, de forma cirúrgica, para afastar ameaças localizadas.

Com efeito, o art. 155, caput, do texto constitucional autoriza - Presidente da República a lançar mão das medidas arroladas no $\S 2^{\circ}$ do art. 156 - que são as mesmas admitidas durante o estado de sítio e o estado de emergência - «para preservar ou, prontamente, restabelecer, em locais determinados e restritos, a ordem pública ou a paz social, ameaçadas ou atingidas por calamidades ou graves perturbações que não justifiquem a decretação dos estados de sítio ou de emergência».

Também nesse caso o Congresso não é chamado a apreciar a suspensão das liberdades individuais, sendo apenas cientificado, dentro de quarenta e oito horas, pelo Presidente da República, das providências tomadas (art. 155,§ $1^{\circ}$ ).

Além disso, é importante salientar que, embora o art. 155, caput, estabeleça o prazo de 60 dias para a duração das medidas de emergência e admita apenas uma prorrogação, na prática, elas podem ser aplicadas indefinidamente. Isso ocorre porque o art. $155, \S 2^{\circ}$, permite que novas medidas sejam determinadas mediante simples comunicação da providência ao Congresso. Ora, como a hipótese que fundamenta a decretação das medidas é bastante abrangente (ordem pública e paz social ameaçadas ou atingidas por calamidades ou graves perturbações), segue-se que não é difícil baixar novas medidas que tenham por base idêntico fato gerador, mesmo porque as agitações sociais, via de regra, eclodem de forma intermitente, num contínuo movimento de fluxo e refluxo. Assim, um mesmo fenômeno que se repita esporadicamente num curto espaço de tempo ou em locais diferentes pode ensejar uma constante renovação das medidas de emergência. É o caso de um surto de greves, por exemplo.

Desse modo, verifica-se que as medidas de emergência, na atual sistemática constitucional, colocam nas mãos do Presidente da República uma soma de poderes somente superada pelo Ato Institucional $\mathrm{n}^{\circ}$ 5/68. De fato, faculta-se ao Chefe de Governo a suspensão das principais garantias individuais com base numa apreciação pessoal e eminentemente subjetiva de fatos definidos de forma vaga na Constituição. A decisão presidencial que baixa essas medidas extremas não sofre qualquer contraste, quer pelo Congresso, quer pelo Judiciário. Afora isso, como foi visto, tais medidas podem ser renovadas, na prática, indefinidamente.

As medidas de emergência, contrariamente aos prognósticos de alguns observadores mais otimistas do processo de abertura política, foram efetivamente aplicadas. No dia 19 de outubro de 1983, o Presidente João Figueiredo assinou o Decreto $\mathrm{n}^{\circ} 88.888$, determinando a adoção das medidas, «de acordo com as necessidades», na área do Distrito Federal, por noventa dias. A iniciativa, segundo o porta-voz da Presidência da República, Carlos Ãtila, foram adotadas com o 
propósito de assegurar o livre funcionamento do Congresso Nacional. $\mathrm{Na}$ mensagem que remeteu à Câmara dos Deputados, justificando o decreto, o Presidente afirmava que «o Distrito Federal está sendo alvo da ação de agitadores recrutados em várias regiões do País, como já aconteceu em ocasiões anteriores, com a intenção de pressionar e intimidar os parlamentares, com risco, até mesmo, para sua integridade física» ${ }^{(44)}$.

Conforme se sabe, as medidas de emergência foram precedidas da rejeiçẳo sistemática, pelos congressistas, de diversos decretos presidenciais relativos à reformulação da política de reajustes salariais, ao longo de votações tumultuadas, às quais compareceram em grande número e de todos os recantos do País, representantes de sindicatos e de outros grupos interessados que, das galerias e nos corredores do Congresso, exerceram vigorosa pressão em prol do repúdio desses instrumentos legais. Com o estabelecimento das medidas de exceção, que dentre outros efeitos restringiu a circulação de pessoas na Capital Federal, o Governo logrou aprovar, depois de pequenas concessões, o Decreto $n^{\circ} 2.065$, de 26 de outubro de 1983, o qual efetivamente colocou em prática uma profunda alteração na política salarial, contemplando reajustes inferiores à variação do índice de inflação. Referendado o decreto, as medidas de emergência esvaziaram-se, na prática, deixando de vigorar no tempo aprazado.

\section{CONCLUSÃO}

Comparado com o estado de sítio, que integra tradicionalmente o arsenal de instrumentos constitucionais de defesa do Estado, deve-se observar que as novas salvaguardas realmente representam um retrocesso, no que diz respeito à garantia dos direitos fundamentais dos cidadãos.

Contudo, em que pesem as características negativas do estado de emergência e das medidas de emergência, deve-se recordar que a sua inserção na Constituição permitiu a supressão dos atos jurídicos de exceção, porquanto tal iniciativa assegurou ao regime um conjunto de instrumentos eficazes para controlar o processo de abertura política. Faz-se necessário acrescentar, ainda, que o simples enquadramento da ação governamental dentro de parâmetros constitucionais, ainda que muito amplos, é inegavelmente um aspecto positivo. Nesse sentido, vale lembrar as lúcidas palavras do professor Francisco Weffort: «A diferença entre um poder presidencial apoiado pelo AI-5 e um poder presidencial cercado pelas 'salvaguardas' é pequena mas não irrelevante. $\bar{E}$ apenas a diferença de qualidade que sempre existe entre um poder ilimitado e um poder regulado, por mais forte que seja este» ${ }^{(45)}$.

(44) Jornal Folha de São Paulo, de 20-10-83, pág. 4.

(45) Apud Délcio de Lima, Brasil: o retrato sem retoque, Rio de Janeiro, Francisco Alves, 1978, págss. 35 e 36 . 